\title{
Comparison of methods of monitoring structure deformations based on tests of a flat plate slab
}

\author{
Damian Nykiel \\ Department of Building Structures; Faculty of Civil and Environmental Engineering \\ and Architecture; Rzeszow University of Technology; \\ 2 Poznańska St., 35-084 Rzeszów, Poland; \\ d.nykiel@prz.edu.pl (D) 0000-0003-2259-5917
}

\begin{abstract}
This work includes a comparison of the methods of monitoring the deformations of a structure on the example of a flat plate slab test. Classic ESG (electrofusion strain gauges) and modern DFOS (distributed fiber optic sensors) were compared. During the research, both types of sensors were used on some of the reinforcing bars. The study aims to indicate the differences between the compared monitoring methods, both in terms of the obtained results and their utility values.
\end{abstract}

Keywords: measurement, deformation, strains, flat plate slab, electrofusion strain gauge, fibre optic gauge

\section{Introduction}

The evolution of measurement techniques provides us with increasingly more opportunities to obtain information on the behaviour of the structure during use or destruction [6]. This includes reinforced concrete structures, where the reinforcing steel embedded in concrete into a large area invisible to the observer. Therefore, for this type of construction, it is important to use measurement techniques that ensure the obtained results are reliable and as extensive as possible. In the case of large and complex elements, the results of experimental tests obtained on research models are the basis for the validation of numerical models. This is of particular importance in reinforced concrete structures, where many processes are not yet fully explained, and the results obtained from FEM models are often inconsistent with test results. Correct measurement and analysis of the obtained results, apart from experimental tests, are also very important during the continuous monitoring of deformations of real structures [1], [4], [7].

This article aims to compare two methods of deformation measurement that can be used in research and continuous monitoring of structures. Based on the conducted research, particular attention was paid to showing the advantages and disadvantages of these methods in the case of measurements of reinforcing bars deformation in reinforced concrete structures. 
The inspiration for this comparison was research conducted at the Rzeszów University of Technology under a contract concluded with CELSA Huta Ostrowiec, a part of project no. POIR.01.02.00-00-0223/-17 entitled: "Manufacture of innovative bars and rings for concrete reinforcement, made in the new class of steel B600B with the implementation of a proprietary technology demonstrator". The conducted research concerned the issue of verification of the influence of reinforcing bars made of $\mathrm{B} 600 \mathrm{~B}$ steel on the development of a progressive catastrophe caused by the removal of the edge support in the flat plate system.

\section{Description of the tested model}

The tested model presented in fig. 1, was a sixteen-section flat plate slab, reflecting the work of the real structure.

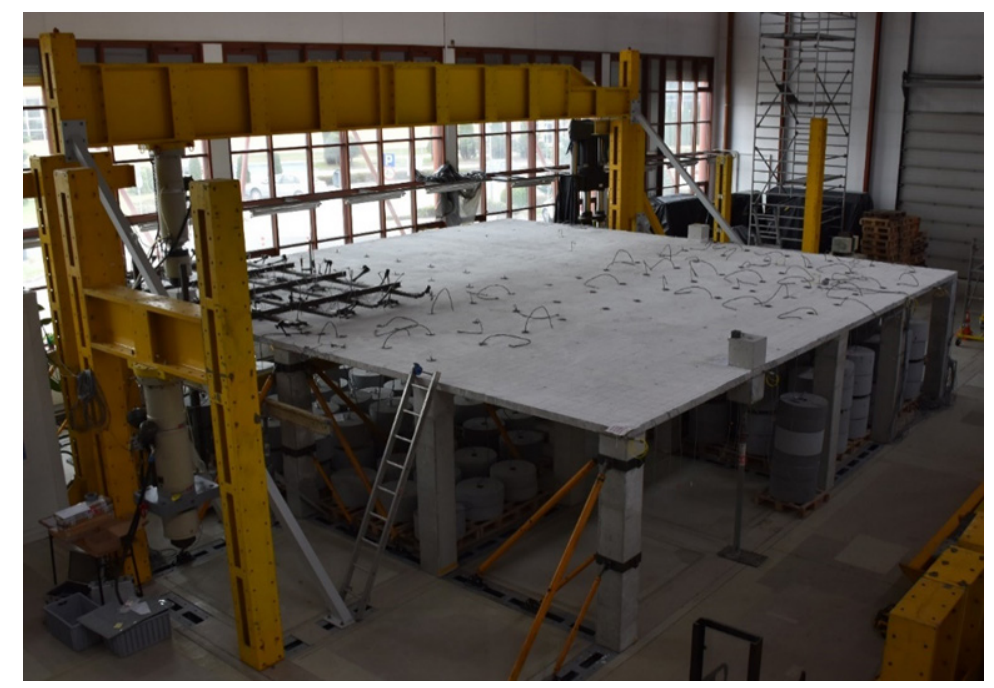

Fig. 1. View of the research model. Source: author

The tested model was made on a scale of 1:3 so that it replicated the real object as accurately as possible. The model assumed a support spacing of $2.4 \mathrm{~m}$, which corresponds to a ceiling span of $7.2 \mathrm{~m}$ commonly used in construction in scale 1:3. The slab thickness was assumed to be $80 \mathrm{~mm}$ and the dimension of prefabricated columns $300 \times 300 \mathrm{~mm}$. The total dimension of the tested slab was $9.9 \times 9.9 \mathrm{~m}$. The research model of the slab was monolithic. The upper part of the columns was monolithized with the slab plate in the laboratory - fig. 2 . The slab reinforcement was designed assuming the ceiling loads had the following values: permanent load $g_{k}=3 \mathrm{kN} / \mathrm{m}^{2}$ and variable load $\mathrm{q}_{\mathrm{k}}=3 \mathrm{kN} / \mathrm{m}^{2}$. Different bonding reinforcement was used in the tested element to create a secondary load-bearing structure in the event of local damage to the edge columns. 


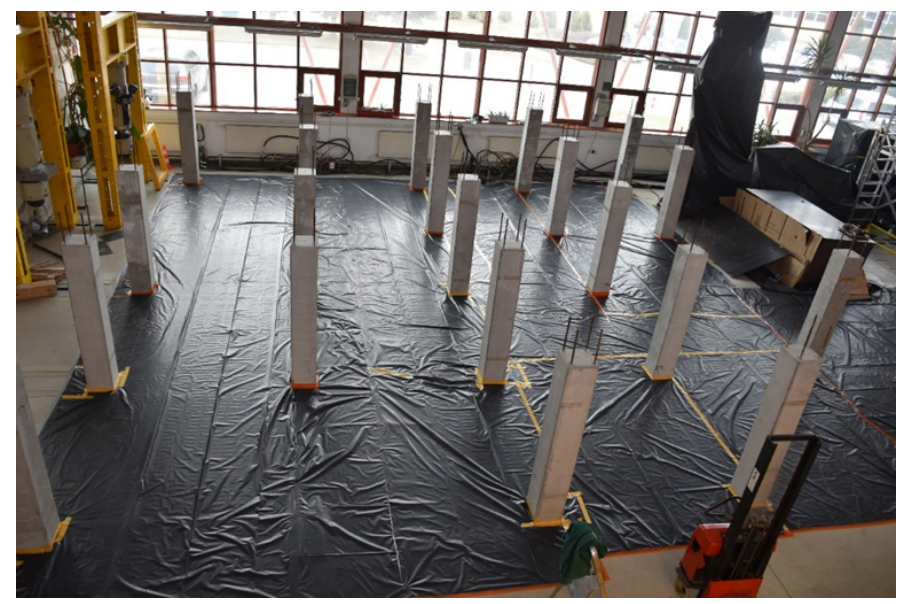

Fig. 2. Prefabricated reinforced concrete columns attached to the strength floor. Source: author

Two methods of ceiling loading were used. In method 1, concrete weights of $200 \mathrm{~kg}$ each were suspended on steel ropes passing through holes prepared in the slab and anchored on its upper surface with washers. These weights were used to simulate permanent and variable loads occurring in this type of structure.

In method 2, after removing the edge column (under full load from method 1), the load with the actuator was implemented. The force from the actuator was transferred to the place of the removed support by a cubic reinforced concrete block imitating the upper storey column.

The results were read with a constant interval determined by lifting weights (method 1) and increasing the force on the actuator every $5 \mathrm{kN}(\operatorname{method} 2)$.

During the conducted research, various measuring techniques, from traditional to modern, were used to measure strains of concrete and steel. The strains of concrete and steel were measured using ESG (electrofusion strain gauges) and DFOS (distributed fiber optic strain) gauges located along the entire length of tested elements.

Electrofusion strain gauges have several advantages that determine their wide range of applications. They are used in tests under static and dynamic loads. The strain gauges are sensitive and their very low weight that does not affect the accuracy of the measurements. Direct transmission of strains to the resistance wire eliminates errors in transmission inaccuracy or slippage that may occur in other strain gauges. Measurements do not depend on the base adopted because result readings are dimensionless. Experience with monitoring systems based on strain measurements shows that there are issues with the interpretation of measurement results and their reliability [9]. As for the strain sensors, an exact connection with monitored elements and stability of their indications is essential. Electrofusion strain gauges are sensitive to operation in a complex state of stress and temperature, therefore improper positioning of the sensors may result in erroneous and unreliable results.

DFOS is a type of fiberoptic sensor that, apart from interferometric sensors and sensors with Bragg grating, is increasingly used in monitoring structures [4]. The fiberoptic measurement technique enables quasi-continuous measurements, consisting of the distribution of up to a dozen measurement points along the sensor of a single fiber (Bragg grating). From an engineering point of view, these distributed measurements, in which the lengths of virtual 
sensors and their distances are so small (row 5-10 mm), can be considered geometrically continuous [5]. This approach allows replacing thousands of traditional sensors with a single optical fiber. For example, on a length of $1 \mathrm{~m}$, it is possible to obtain information about the strain's value even at 200 measurement points. This measurement technique also allows recording and locating cracks in the concrete [3].

\section{Methods of deformation measurement}

During the conducted studies, electrofusion strain gauges and fiberoptic strain gauges were used to measure strains. In the tested element, more than 100 electrofusion strain gauges were glued onto reinforcing steel and about 50 onto concrete. 19 fiberoptic strain gauges were also glued onto reinforcing steel and 4 onto concrete. Fig. 3 and fig. 4 show a strain gauges arrangement scheme used only on reinforcing steel.

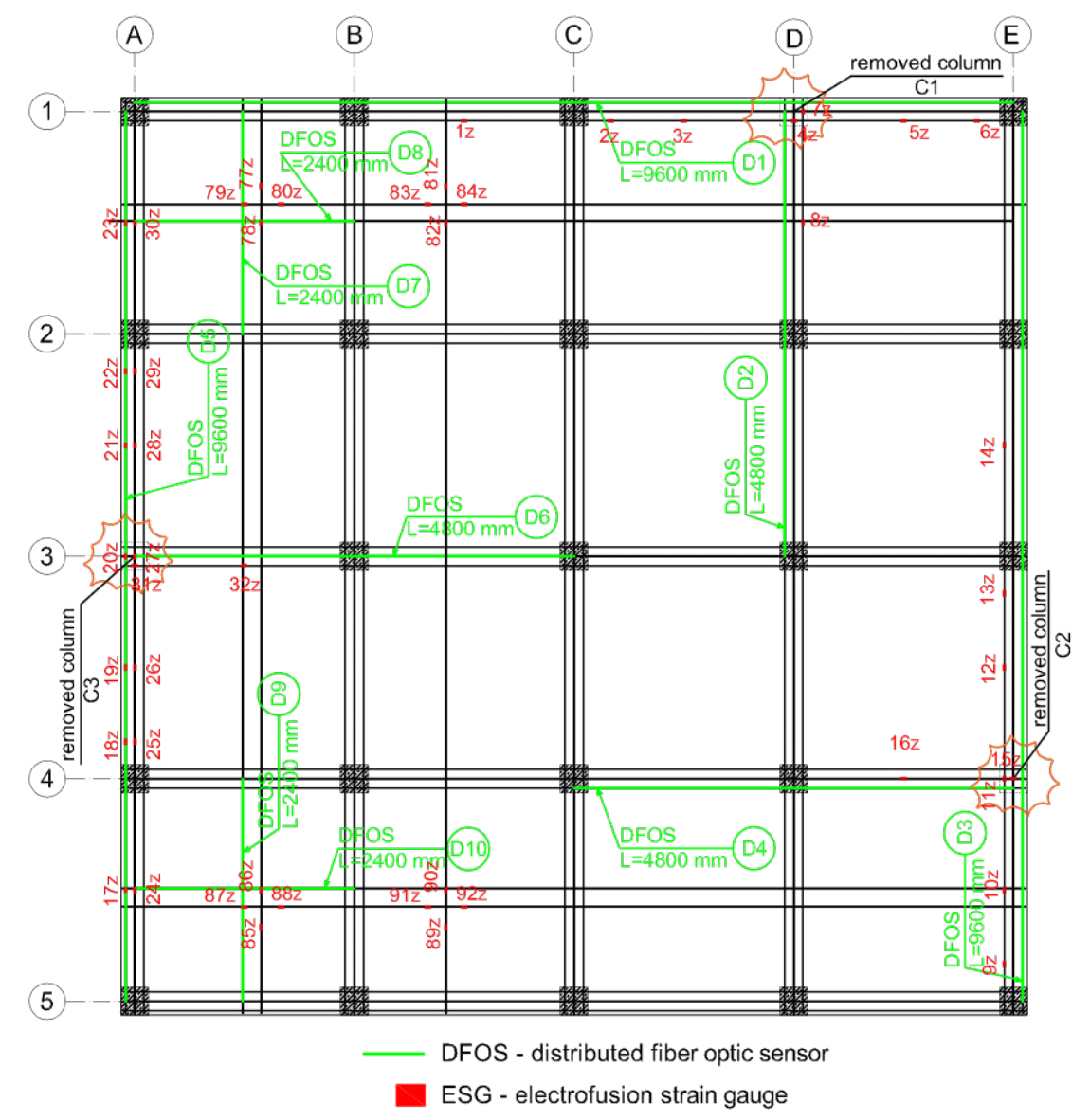

Fig. 3. Strain gauges arrangement scheme on the bottom reinforcement. Source: author 


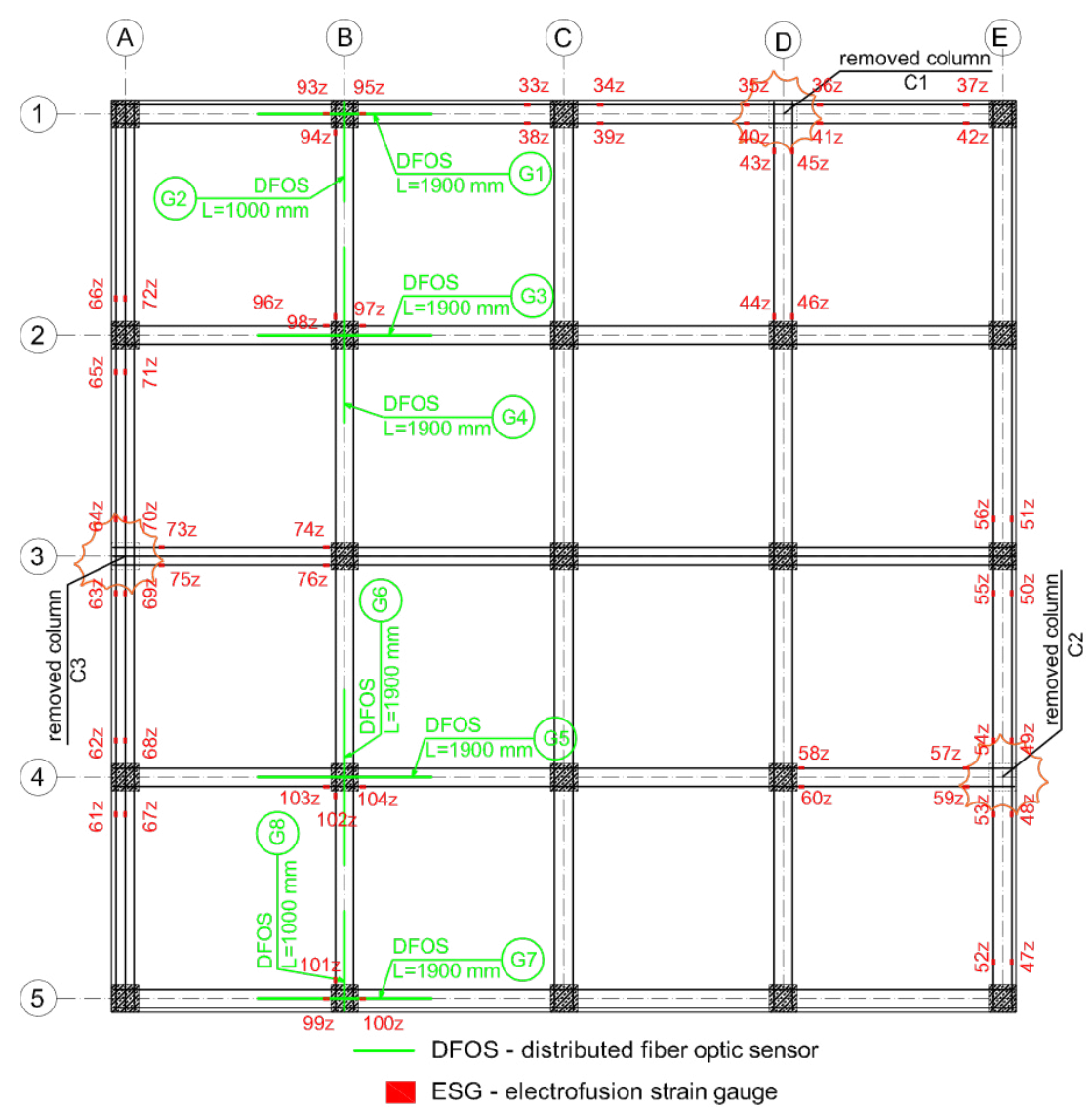

Fig. 4. Strain gauges arrangement scheme on the top reinforcement. Source: author

TFs 5/120 electrofusion film strain gauges were used to measure the strains of reinforcing steel and TFs 60/120 to measure the strains of concrete produced by TENMEX. The strain gauges were glued to the reinforcement in accordance with the manufacturer's instructions. The strain gauges bonding was performed on the already prepared reinforcement of the slab. The surface of the rod was cleaned by grinding, then smoothed with sandpaper no. 300-400 in two mutually perpendicular directions. The surface was degreased with ATEPO Z-12 remover and WBT-500 swabs used once. A drop of ATEPO Z-03 neutralizer was applied, spread out and allowed to dry. A strain gauge was glued onto the prepared surface with cyanoacrylate adhesive TB-1731. Then, the cables were soldered to the ends of the strain gauge and secured against adverse weather conditions and mechanical damage with self-adhesive ALG-2 shielding and protection tape. For each strain gauge, temperature compensation strain gauges were used, glued on the same material and surface-connected to the tested element. Fig. 5 shows the prepared electrofusion strain gauges before concreting. 


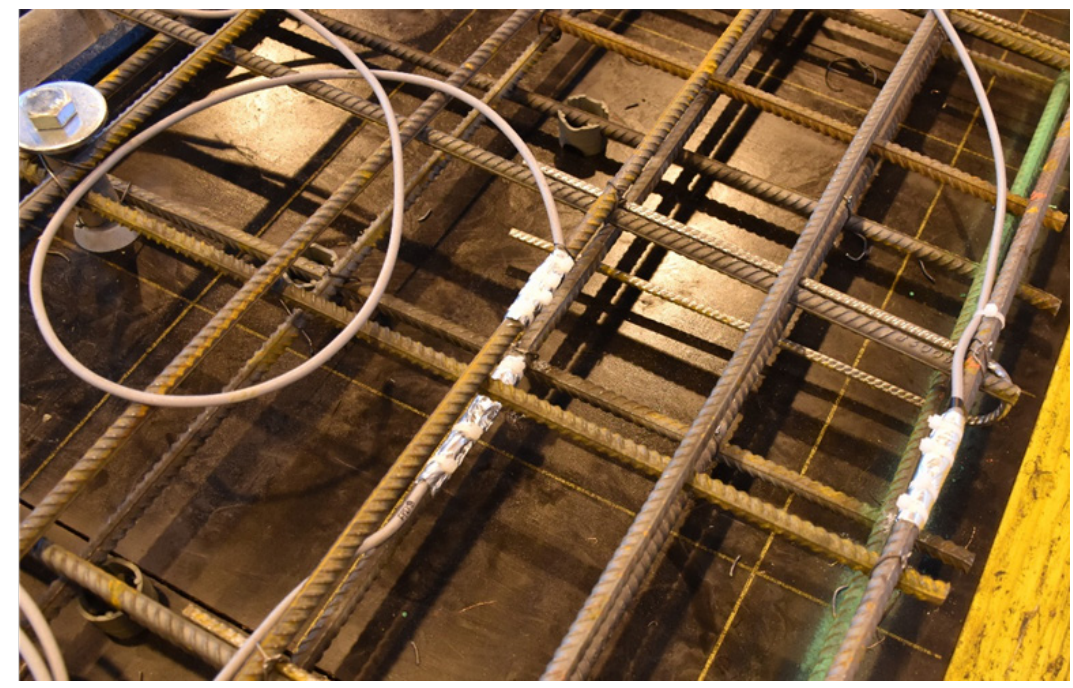

Fig. 5. View of electrofusion strain gauges glued to the reinforcement. Source: author

Another group of sensors used to measure strains are optical fiber strain gauges, in which the basic element is a standard optical fiber, a thin glass fiber transmitting light in its core. DFOS (distributed fiber optic sensors) were used in the conducted research - fig. 6 .

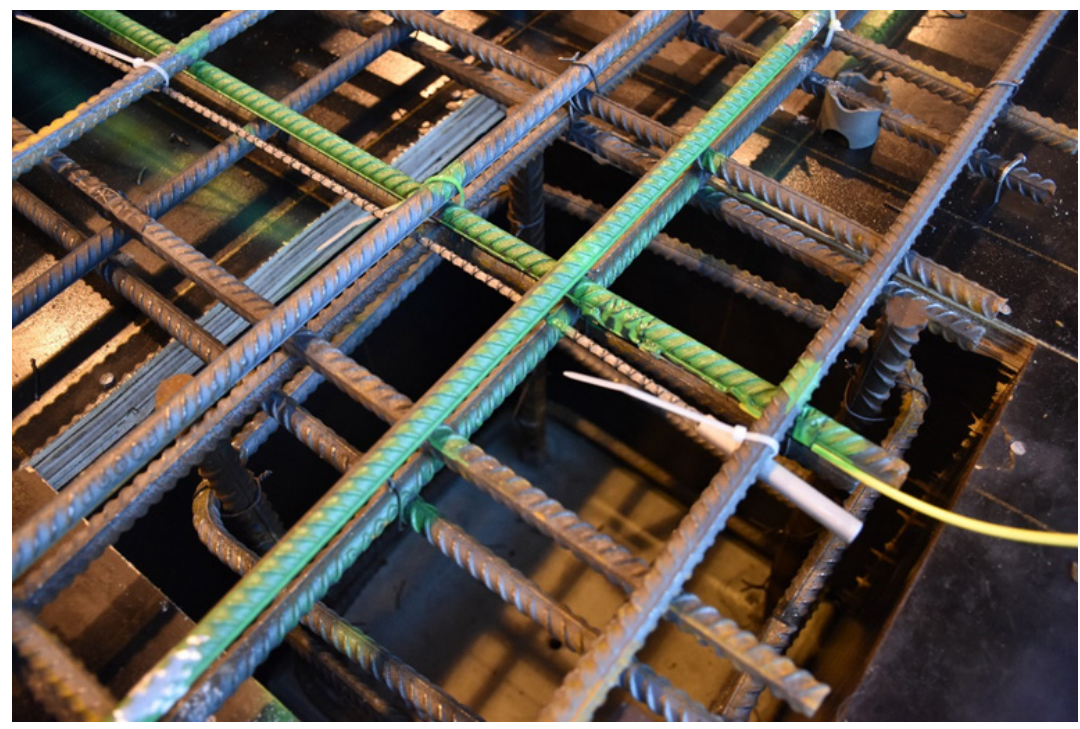

Fig. 6. View of fibre optic strain gauge glued to the reinforcement. Source: author

The installation and recording of results from fiberoptic sensors were handled by an external company - SHM System. SM 9/125, OFS, ITU-G657.A1 fiber sensors were glued to the longitudinal ribs of rebars with a thin layer of epoxy resin. Strain results were recorded using OBR4600 reflectometer manufactured by LUNA Technologies in the unit: 
$\mu \varepsilon=10^{-6}=0.0001 \%=0.001 \%=0.001 \mathrm{~mm} / \mathrm{m}$. The scan range was from $1,545,518$ to $1,588,258 \mathrm{~nm}$, the group refractive index was 1.47 , and the gain was $24 \mathrm{~dB}$. Optical fiber spatial resolution $-10 \mathrm{~mm}$, meaning 100 sensors per $1 \mathrm{~m}$ of fiber. The optical fibers were glued on selected rods which, after the resin had dried, were inserted into the formwork and tied to the remaining reinforcement.

Before concreting, the operation of all strain gauges on reinforcing steel was checked and no damage was noted. A few days after concreting, another check was made. It turned out that all electrofusion strain gauges work well, while some fiber optic sensors were damaged. A more thorough inspection showed damage (or partial damage) of sensors: D1, D4, D5, D10, G2, G4, and G7. This represents $40 \%$ of all DFOS sensors used.

\section{Results obtained}

Examples of the strain measuring results of reinforcing steel with electrofusion strain gauges are shown in fig. 7. These are the results of several measurement points located on the bottom reinforcement, located in the tested slab.

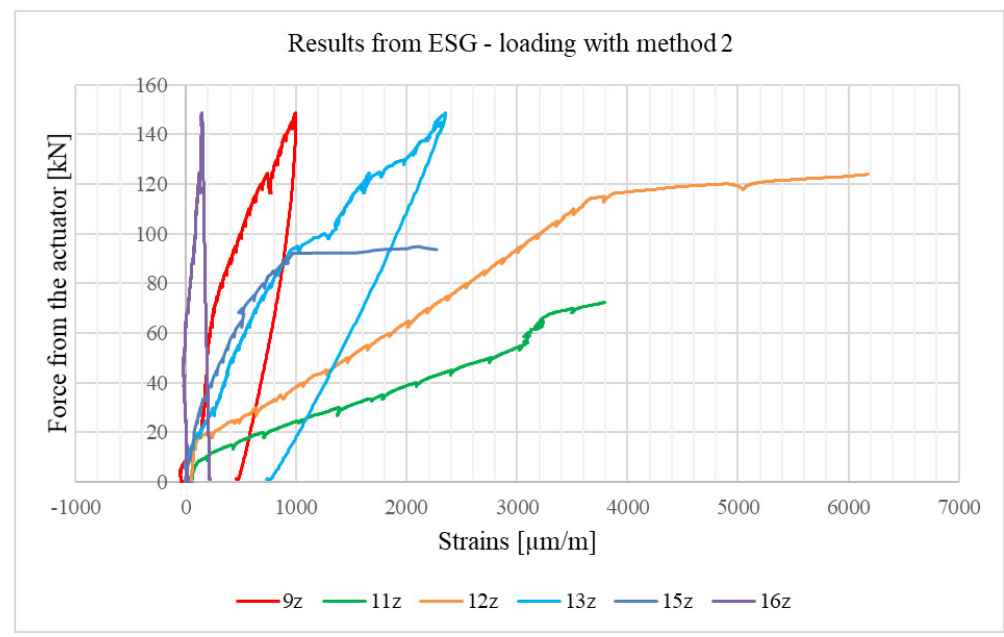

Fig. 7. Results from electrofusion strain gauges. Strain gauges glued to different bars of the bottom reinforcement - loading method 2. Source: author

As can be seen, three strain gauges broke during the tests. The $15 \mathrm{z}$ strain gauge was damaged with relatively small strains amounting to only $0.1 \%$, while the $11 \mathrm{z}$ and $12 \mathrm{z}$ strain gauges with strains of about $0.4 \%$, which can be equated with reaching the yield point by the reinforcing steel. The failure mechanism at $0.4 \%$ strains presented in fig. 7 . was typical for most strain gauges used in the research.

Fig. 9 shows the results of strain measurements for the selected two points placed on the rebar, obtained with electrofusion strain gauges. On the other hand, fig. 8. shows the results of strains measurements with the use of fiberoptic sensors. Obtained results are for the entire length of the tested reinforcing bar, the same one in which the strain gauges shown in fig. 9 . were placed. The result of deformation is presented depending on 9 load stages, determined by the suspension of concrete weights simulating permanent and variable loads (method 1). 


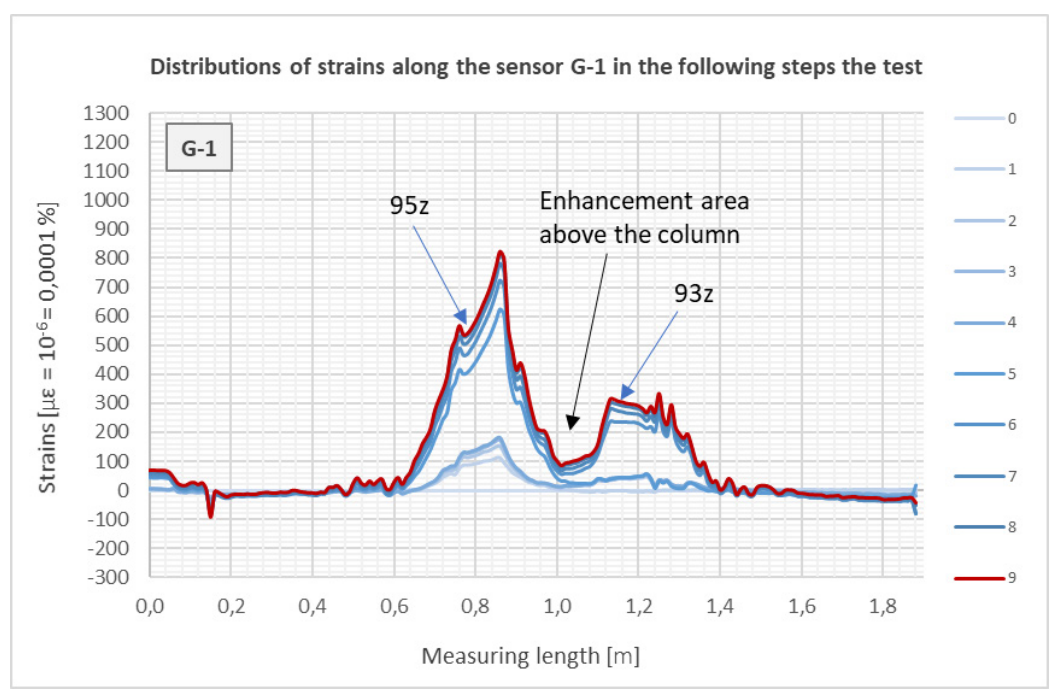

Fig. 8. Results from the DFOS-G1 - loading method 1. Source: author

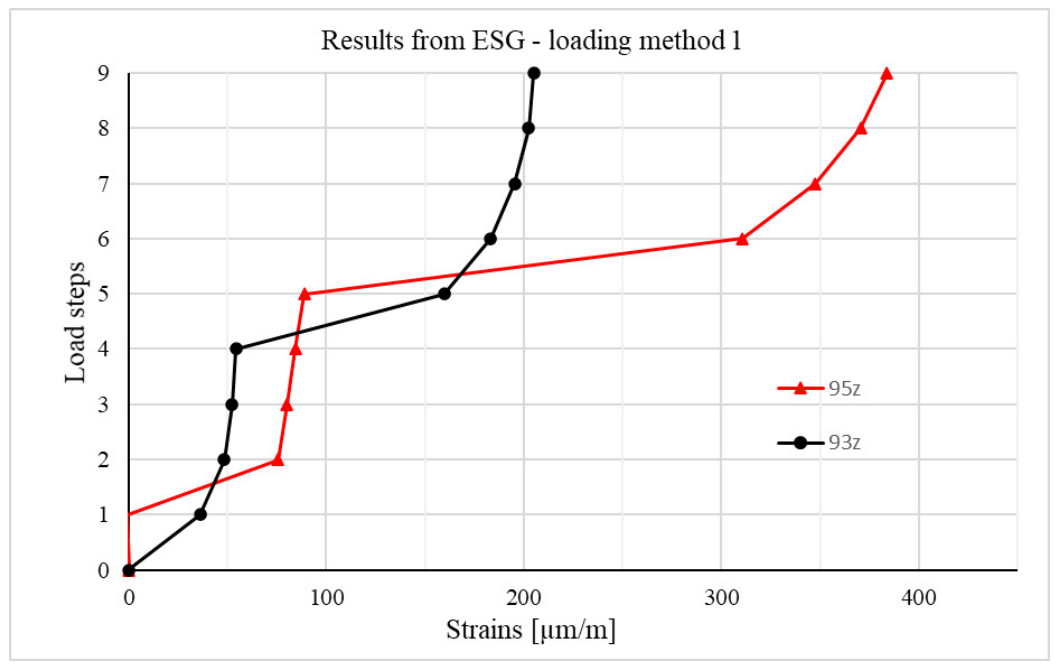

Fig. 9. Results from the $93 z$ and $95 z$ electrofusion strain gauge. Strain gauges on the top reinforcement bar at a distance of $75 \mathrm{~cm}$ and $115 \mathrm{~cm}$ from the beginning of the bar $(5 \mathrm{~cm}$ behind the face of the column)- loading method 1. Source: author

As can be seen, the strains obtained, e.g., step 9, are different depending on the measurement technique. From electrofusion strain gauges, the strains for points $93 \mathrm{z}$ and $95 \mathrm{z}$ are respectively: approximately $380 \mu \mathrm{m} / \mathrm{m}$ and $200 \mu \mathrm{m} / \mathrm{m}$, while those obtained from fiberoptic sensors are larger and amount to $95 \mathrm{z}=530 \mu \mathrm{m} / \mathrm{m}, 93 \mathrm{z}=300 \mu \mathrm{m} / \mathrm{m}$. When analysing the strains of the entire length of the bar, more interesting processes can be noticed, such as a decrease 
in strains associated with the enhancement area above the column, or the complete loss of strains in the initial and end areas of the bar.

Continuous measurement allows you to see differences in the deformability of bars, which seem to be the same. This process was observed during tests carried out on three bars perpendicular to the removed supports. Fig. 10, fig. 11, and fig. 12 show strains diagrams obtained from fiber optic sensors placed on the analysed reinforcement bars during a load of $90 \mathrm{kN}$.

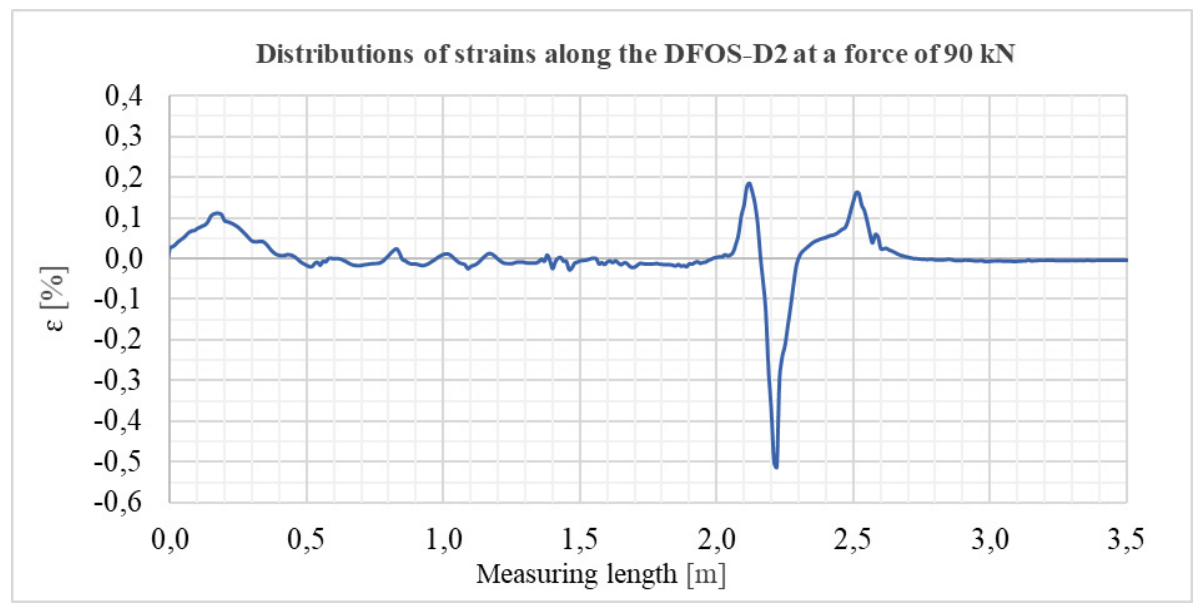

Fig. 10. Distribution of strains on the bottom reinforcement bar obtained from the DFOS-D2 sensor with an actuator load of $90 \mathrm{kN}$. Source: author

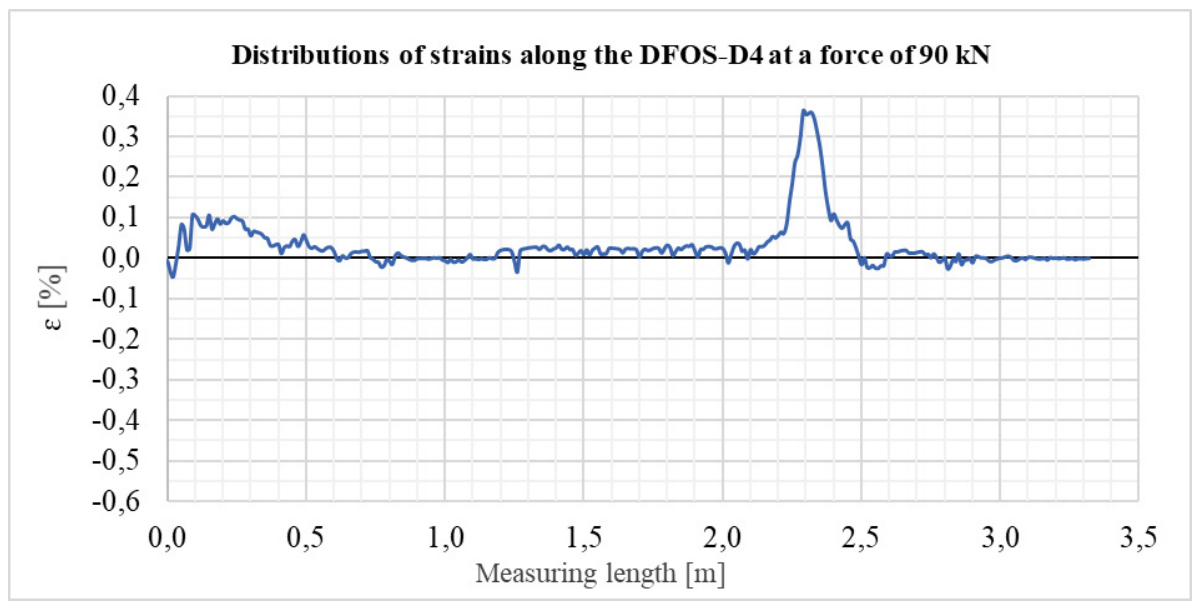

Fig. 11. Distribution of strains on the bottom reinforcement bar obtained from the DFOS-D4 sensor with an actuator load of $90 \mathrm{kN}$. Source: author 


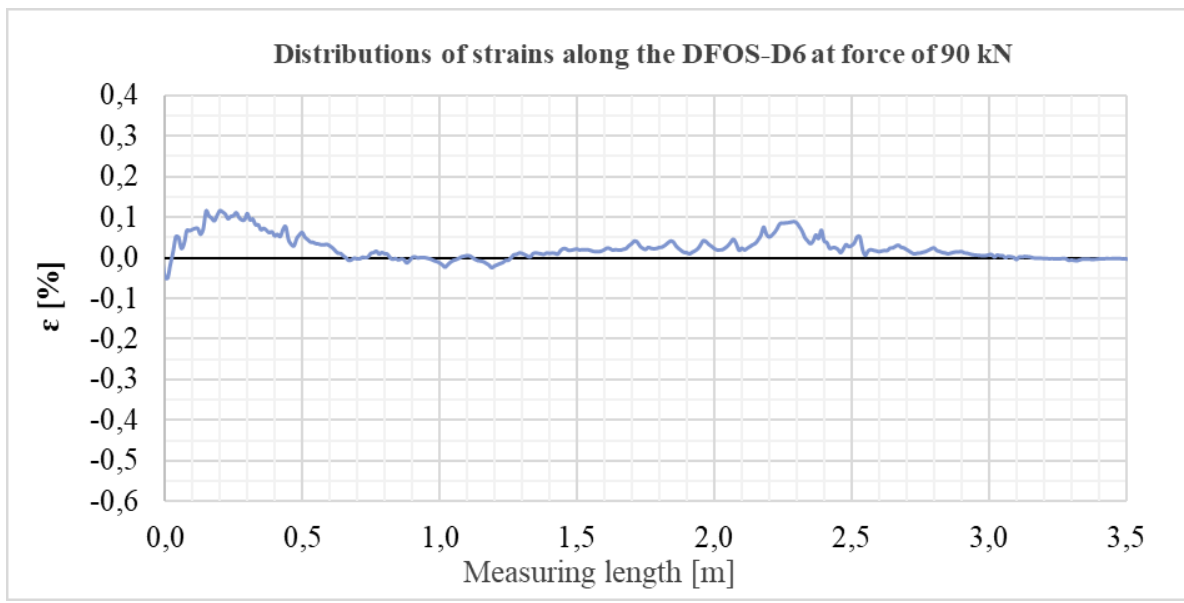

Fig. 12. Distribution of strains on the bottom reinforcement bar obtained from the DFOS-D6 sensor with an actuator load of $90 \mathrm{kN}$. Source: author

The charts presented above allow to read the tensile strains in the place where the actuator is applied, amounting to approximately $0.1 \%$ in each case. The situation is different over the support. In the case of the DFOS-D4 sensor, the expected deformation course of almost $0.4 \%$ can be seen. However, the DFOS-D2 sensor shows a completely different course. The rapid jump of strains in the compression direction to the value of $-0.5 \%$ could be caused by the local influence of transverse reinforcement or the local pressure of the aggregate against the sensor. The local nature of this process highlights the fact strains before and after the "jump" amount to approximately $0.4 \%$ - similar to the DFOS-D4 sensor. The strains above the support obtained from the sensor DFOS-D6 are significantly lower. This seemingly insignificant fact had an impact on the change in the strains of the DFOS-D6 bar in relation to DFOS-D2 and DFOS-D4. During the tests, the reinforced concrete central column was removed and replaced with a steel column loosely connected to the slab. The lack of a rigid connection enabled the slab to rotate over the support and, as a result, the measured deformation of the bar was 4 times smaller.

As shown, the analysis of the results obtained from continuous measurements over the entire length of the test bar has allowed the observation of the processes impossible to detect with point strain gauges. Another disadvantage of commonly used electrofusion strain gauges is their high sensitivity when working in a complex stress state.

To analyse the processes that were impossible to capture directly during the research, a numerical model of the tested flat plate slab was created. The numerical model was devised in the ATENA program and validated based on the results obtained from experimental measurements. Fig. 13 shows the deformation of reinforcement bars during tests, obtained from numerical simulations. 


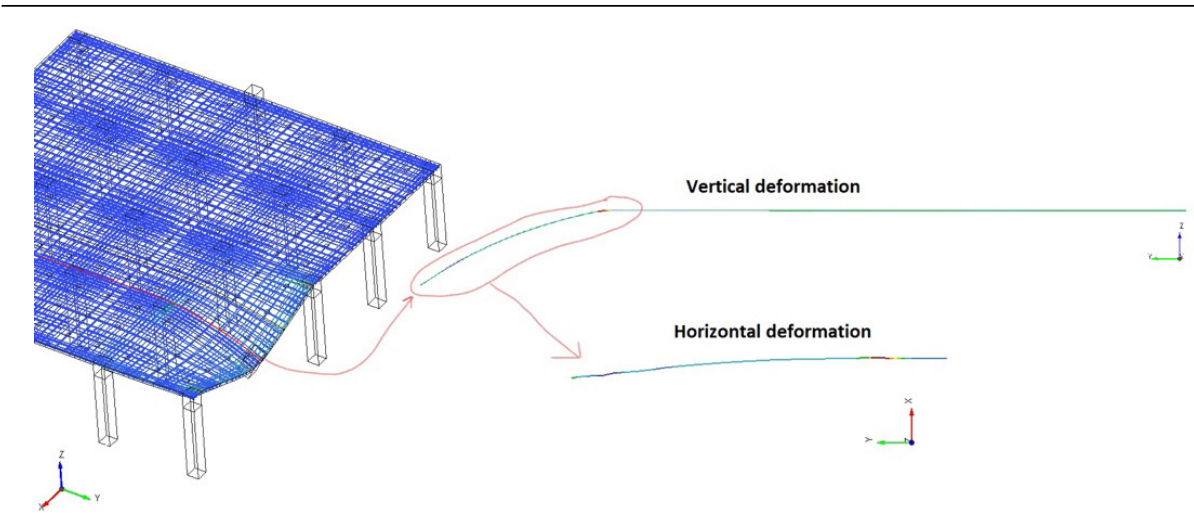

Fig. 13. Images of reinforcing bar deformation obtained from the numerical model using the ATENA program. Source: author

As shown in the figure, the reinforcement bars have undergone deformations along the bar axis as well as lateral deformations. This means that the tested element works in a complex state of stress. Therefore, electrofusion strain gauges adapted to work in the uniaxial state of stress can provide erroneous results. Conducted tests confirmed that the results obtained in many cases were defective and strain gauges were destroyed at the limit strain values lower than those provided by the manufacturer. This process was not observed in the case of fiberoptic strain gauges. Conducted research and obtained results have shown one more important aspect that should be taken into account when planning the measurements - the place on the bar to which the fiberoptic strain gauge will be glued. In conducted research, the fiberoptic strain gauges were glued onto the longitudinal ribs of the reinforcing bars and then placed in the plate in such a way, that the strain gauge was located on the side edge. During formwork and concrete pouring, it is possible to rotate the bar around its axis and the glued sensor will be located on the lower or upper edge, and this may have a significant impact on obtained results and their comparison.

\section{Summary and conclusions}

Summarizing presented methods of monitoring the deformation of the structure, it can be noticed that new measurement techniques are superior to the traditional ones. The obtained results of strains of reinforcing steel from DFOS provide more information than classic electrofusion strain gauges. The fiberoptic sensor enables strain analysis along the entire length of the rebar, capturing the places of maximum strains and enhancement areas. During the measurements, a greater limiting strain of the DFOS sensors was also noticed, practically in every measured element, the measurement was possible up to the strains of about $4 \%$. Measurement of such large strains in the case of electrofusion strain gauges was impossible, most of them were destroyed at strains of about $0.4 \%$, i.e., when the reinforcing steel became plastic or cracks appeared in the concrete. In contrast, a disadvantage of optical fiber sensors is their high sensitivity to mechanical factors. A significant part of the fiber optic sensors located on the reinforcing steel was damaged during pouring and vibrating the concrete of the slab and during auxiliary works related to it. Therefore, when using fiber optic sensors, special attention should be paid to the manufacturing technology and measures to protect the sensor against 
mechanical damage. Table 1 summarizes the advantages and disadvantages of the methods used to measure deformation.

Table 1. Collective summary of advantages and disadvantages of electrofusion and fiber optic strain gauges

\begin{tabular}{ll}
\hline ESG & DFOS \\
\hline Point results & Results along the entire length of the element \\
\hline Lower strains limit $\approx 0.4 \%$ & Higher strains limit $>4 \%$ \\
\hline No crack detection & Possibility to locate and analyse cracks \\
\hline Hardiness to mechanical factors & Sensitivity to mechanical factors \\
\hline Low cost of recording the results & High cost of recording the results \\
\hline Sensitivity to working in a complex stress state & Hardiness to work in a complex stress state \\
\hline
\end{tabular}

\section{References}

[1] Chróścielewski J. et al., "Badania wiaduktu nad torami kolejowymi przy PGE Arena w Gdańsku podczas jego realizacji”, Budownictwo i Architektura, vol. 12(2), 2013, s. 015-022. https://doi. org/10.35784/bud-arch.2065

[2] Bado, M.F. and Casas, J.R., "A Review of Recent Distributed Optical Fiber Sensors Applications for Civil Engineering Structural Health Monitoring”, Sensors, vol. 21, 2021, 1818. https://doi. org $/ 10.3390 / \mathrm{s} 21051818$

[3] Bassil A. et al., Distributed Fiber Optics Sensing and Coda Wave Interferometry Techniques for Damage Monitoring in Concrete Structures, Sensors, vol. 19, 2019, 356. https://doi.org/10.3390/ s19020356

[4] Kulpa, M. and Siwowski T., "Badania pomostów kompozytowych do zastosowań w mostach drogowych", Budownictwo i Architektura, 13(2), 2014, pp. 231-238. https://doi.org/10.35784/ bud-arch. 1900

[5] López-Higuera J., Cobo L., Incera A., Cobo A., "Fiber optic sensors in structural health monitoring”, Journal of Lightwave Technology, vol. 29, no. 4, 15 Feb. 2011, pp. 587-608. https://doi. org/10.1109/JLT.2011.2106479.

[6] Mesquita, E. et al., "Global overview on advances in structural health monitoring platforms", $J$ Civil Struct Health Monit, vol. 6(3), 2016, pp. 461-475. https://doi.org/10.1007/s13349-016-0184-5

[7] Poneta P., and Siwowski T., "Badania dźwigara mostowego z kompozytów FRP pod obciążeniem statycznym”, Budownictwo i Architektura, 13(2), 2014, pp. 291-298. https://doi.org/10.35784/ bud-arch.1907

[8] Siwowski T., Sieńko R., Bednarski Ł., "System monitorowania mostów kompozytowych z wykorzystaniem światłowodowych czujników odkształceń", Most, May 2017, pp. 24-27.

[9] Wierzbicki S., "Monitoring konstrukcji stalowych. Część 3 - Metody pomiarowe - pomiary odkształceń", Builder, R. 20, September 2016, pp. 82-84. 